\title{
ECO-INNOVATION IN BIOMASS RESEARCH PROJECTS
}

\author{
Yannou-Le Bris, Gwenola (1); Treves, Viviane (2); Meynard, Jean-Marc (2); Cerf, Marianne (2)
}

1: AgroParisTech; 2: INRA

\begin{abstract}
This paper tackles two questions. Our first question addresses the multi-actor activity that is visibly required for building radical innovations like eco-innovation. Our second question addresses the tricky issue of how to assess contribution to ecological transition when innovation projects are still in the fuzzy early-upstream phase. In this aim four research projects are selected and analyzed in this paper because they share a common scope - the development of new processes or materials tied to the conversion of biomass. Through the analysis of the actors interactions conducted in these projects, of their perimeters, of their sustainability objectives and of their results we show a limit of the eco-innovation capacity of these projects linked to the limits of their crossdisciplinarity.
\end{abstract}

Keywords: Eco-innovation, Collaborative design, Sustainability, Research methodologies and methods

Contact:

Yannou-Le Bris, Gwenola

AgroParisTech

Laboratoire Génie Industriel

France

gwenola.yannou-lebris@agroparistech.fr 


\section{INTRODUCTION}

Public research funding plays a lead role in driving innovation in France, offering structural and functional support for the research community (Gaglio, 2011; Thiard et al., 2013). The French national research and innovation strategy is effectively a policy roadmap to support an ecological transition towards efficient resource management and food security. In the life sciences sector, the ecological transition hinges on emerging radical innovations and on mobilizing a diverse array of ingroup and outgroup organizations engaged in bioscience, bio-industry and bio-economy. As stated by Meynard et al. (2017), this raises the need to rethink the modes of innovation early on in upstream research phases in order to allow better connections between stakeholders in later downstream phases and thereby accelerate the diffusion of the innovations that could effectively contribute to the ecological transition for green growth. This paper tackles two questions.

Our first question addresses the innovation process and multi-actor activity that are visibly required for building radical innovations like eco-innovations. We use an analysis of several case-projects to study how this multi-actor activity plays out through project-task components. As we employed a purely qualitative approach and analysed only a handful of projects, we have been careful not to overstretch the conclusions, but our analysis does have the merit of pointing to hypotheses that future research could check or challenge.

Our second question addresses the tricky issue of how to assess contribution to ecological transition when innovation projects are still in the fuzzy early-upstream phase. Here we focus on some projects of TRL 1-4 (TRL for Technology Readiness Levels). Indeed these projects maturity was between "Basic Research Technology" level and "Technology Development" level. None of the projects considered has yet reach a level of being on its market. These projects articulate new technologies, new technology stacks, or new organizational models, where contributing to the ecological transition may be the direct project brief or just a component of the design requirements. Here we investigate how this contribution is analysed and articulated in the case-study projects.

\section{LITERATURE}

These research projects analysed in this paper share a common scope-the development of new processes or materials tied to the conversion of biomass that could contribute to the development of more sustainable systems. To understand our analysis in terms of the concepts, constructs and artifacts analysed, we begin with a brief review of the literature to cover two issues. The first is to position the framework of innovation systems analysis adopted for this scholarship. The second is to situate the critical role of crossdisciplinarity in research and innovation projects for ecological transitioning.

\subsection{Analyzing the innovation system}

One way to illustrate the final defining features of an innovation is to map its path through the innovation system that brought it to life. Bergek et al. (2008) acknowledge that this innovation system is composed of "actors, networks and institutions"-i.e. a socio-technical system-"contributing to the overall function of developing, diffusing and utilizing new products..." through knowledge, product technology, or both. In this kind of approach, the innovation is not the only element to study in order to understand the innovation process being deployed by studying its environment, through the context it frames and the networks it underpins, can also serve to understand the trajectory of the innovation. Klein et al. (2005) found four sources of potential innovation system failure tied to socio-technical system factors, including infrastructural failure (tied to the actors and artifacts), interaction failure (tied to the networks), lack of public funding (tied to public policy strategies) and capabilities failure (tied to the actors). Beyond the role of the pre-existing socio-technical system associated with the innovation, the scholars also points out four other factors influencing innovation outcomes:

- How the innovation objectives are defined, chiefly how the rationales and paths to operationalizing the 'change of scale' are mobilized in order to sharpen the definition of the problem to be solved (Dubois, 2005); In our case this approach of the problem is characterised by taking into account simultaneously of upstream and downstream of agrifood value chains with the objective of coupled innovation (innovation made possible by cooperation between the actors in these two areas of the value chains) (Meynard et al., 2017) 
- Characteristics of the human actors involved in the network: life path and career path (Enengel et al., 2011) or engagement-values-expectations-goals-skillsets (Callon et al., 1999; Meynard et al., 2017; Bonnetto, 2017; Reed, et al., 2009);

- Characteristics of the non-human (object, equipment, information, institutions, natural resources ...) factors involved in the network (Callon et al., 1999).

- Types of project outcomes/deliverables, which in research will mean producing and sharing knowledge, training graduates, new scientific and methodological instruments, new networks created and social interactions accelerated, increase in scientific and technological problemsolving capacity, startups and entrepreneurship and mobilization of social knowledge.

In summary, analysing innovation systems implies taking into account the way in which the problem is formulated, the structure of the socio-technical system in which the innovation will be integrated, the interactions that arise during the project between the different actors (human and non-human), the tangible and intangible results that they produce. Finally in this work a focus is done on how an objective of producing innovation contributing to sustainability in biomass use intervenes in the structures and dynamics of these innovation systems.

\subsection{Vectors of sustainable innovation in food systems}

Food systems are heavily constrained by huge challenges in terms of growing populations to feed (FAO, 2015) and growing pressure to protect natural ecosystems, and so the emergence and development of eco-innovations has become the pivotal challenge for all food systems (Yannou-Le Bris and Serhan 2018). Carillo-Hermosilla et al. (2010) calls these innovations 'radical' as they create value by rendering existing competencies obsolete and replacing the old systems by new systems and networks. The emergence of these innovations hinges on creating new types of knowledge produced through and implemented within the innovation process. The broad consensus is that these innovation processes have to be open-community and cross-disciplinary (Yannou-Le Bris and Serhan 2018). Food-farming systems require crossdisciplinarity because they need to simultaneously rethink each and every subsystem from the ground up, through their technical, scientific, organizational, social and institutional layers (Meynard et al., 2016). Projects like these therefore syndicate industry professionals, associations, and consumers (Roelofsen et al., 2011), obviously alongside scientists from various disciplines. According to Tress (2005), it is this fresh new form of collaboration that enables the actor-stakeholders to learn to think and act outside the box and create new sources of problem-solving know-how. The objective of this kind of project often involves switching and stacking knowledge-sets into creative combinations. The combination targeted mobilizes not just that explicit knowledge that is transmitted in formal language but also the tacit knowledge that Nonaka et al. (1996) describe as personal and internalized, difficult to codify, and therefore difficult to transmit. Transmission can only be done through exchange, and therefore socialization, or through a coordinated codification effort.

Bengt (1998) notes that this kind of cross-disciplinary project can foster negative perceptions from pure researchers who are uncomfortable with this level of risk-taking, and Hering et al. (2012) underlines their propensity to overrun the financial budget as well as the allocated time budget.

Considering the interdisciplinary nature of the challenges for sustainable innovations, it can be assumed that innovation projects of this type involve a high diversity of actors who maintain numerous exchanges associated with a high level of knowledge sharing.

\section{MATERIAL AND METHOD}

\subsection{Selection of projects analysed}

This research is based on an analysis of four case-projects. These four projects were selected from a shortlist of 9 projects that had originally been identified via a call for proposals sent out to colleagues working in agronomy, biomass conversion processes and food formulation. Interviews, led using an interview guide, were conducted with one or two lead scholarss from each project in order to capture their specific characteristics in terms of: importance of biomass conversion as a function in their technology; importance lent to the ecological transition in this use of biomass; readiness of projectengaged actor-stakeholders to participate to interview; diversity of the actors represented through selected projects; project size limit (we could not envisage having to lead any more than three or four 
interviews per project in the time-window to get a good all-round vision of its innovation flow). Once candidate projects were selected, we narrowed their scope of analysis, i.e. when a project—as defined by the interviewee - contained several clear-cut stages, we chose to focus in on just one single stage. For all four projects, this strategy enabled us to focus on a single project built around a single $\mathrm{PhD}$ student, which has the virtue of offering easily definable boundaries.

The objectives of the four projects analysed were:

- $\quad$ Project 1: Development of a new molecule-of-interest production/extraction process.

- Project 2: Development of a new industrial co-product value-streaming process.

- Project 3: Development of a new biodegradable bio-based plastic material.

- Project 4: Development of a flexible mode of value-streaming wheat flour/legume flour composites according to the raw-material characteristics.

\subsection{Data collection and information capture}

Preliminary interviews served to identify the lead actors of each project, i.e. (1) one person per organization/institution engaged in the project, (2) the focal PhD student, (3) the thesis supervisors, (4) the associate researchers, and any other person named as important during the interviews.

We ultimately managed to conduct 23 interviews, as illustrated in Table 1.

Table 1. Number and types of interviews conducted per project

\begin{tabular}{|l|l|l|l|l|}
\hline Project & $\begin{array}{l}\text { PhD } \\
\text { student }\end{array}$ & $\begin{array}{l}\text { Thesis } \\
\text { supervisor }\end{array}$ & $\begin{array}{l}\text { Associate } \\
\text { researcher }\end{array}$ & Partner representative \\
\hline$\# 1$ & 1 & 2 & 2 & 1 \\
\hline$\# 2$ & 1 & 1 & 1 & 2 \\
\hline$\# 3$ & 1 & 1 & 1 & 3 \\
\hline$\# 4$ & 1 & 2 & 0 & 3 \\
\hline
\end{tabular}

Interviews were semi-structured, conducted by working from a standard interview guide with topics and questions asked in different ways for different participants targeting the innovation systems characteristics described in section 2.1. Each interview was audiotaped and transcribed verbatim. Based on this first-hand evidence, each project was analysed and then written up into a case study on the following template:

1. Brief of the project's scientific objectives.

2. Project initiation.

3. Descriptive data on the network of actors involved.

4. Descriptive data on the material outcomes and on scientific and mainstream diffusion.

5. Any project implementations followed through.

The actor-stakeholders network was described by categorizing the actors in a typology scheme borrowing and building on the scheme used by Enengel et al. (2011). The scheme features:

- The lead scientists actually conducting the scientific research;

- $\quad$ The science consultants backing up the lead scientists;

- Subcontractors on hand to execute a scientific or technical order;

- Professional expects who bring any extra information or knowledge input needed;

- The financial backers: Institutions or their representatives who fund the research projects.

- The scientific community, which is represented whenever mobilized for special input.

Working up from that basis, we produced the kind of diagram given in Figure 1 (which illustrates case-project \#1).

\subsection{Intermediate analysis of projects}

Such representations were produced for each of the projects. Building these representations aimed to easily understand the diversity of the actors involved in the projects and highlighted their degrees of involvement (according to their inclusion or exclusion from the dotted line framework), the nature of the elements exchanged between them. These representations, analysed in transversal reading way, made it possible to highlight the central role of doctoral students as pivots of transdisciplinarity and the relatively low openness of projects to non-scientific stakeholders. 


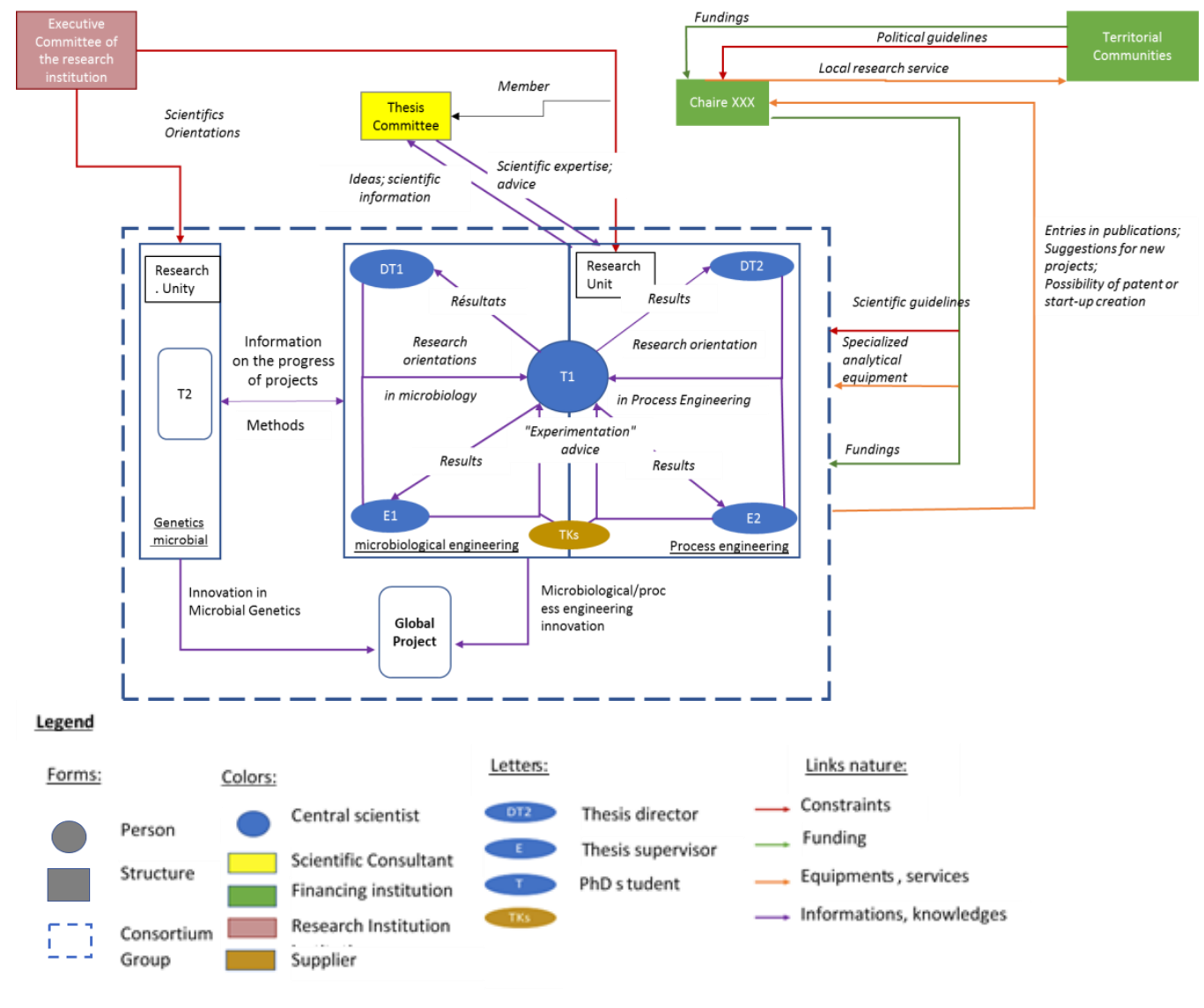

Figure 1. Example of the network representation used to analyse stakeholders involved in the projects

\subsection{Method of analysis}

We led a comparative analysis of each case-project to try to tease out the key factors for successful and unsuccessful delivery of concepts or prototypes that could lead to coupled and radical eco-innovations.

Our assessment only focused on the artefact that the consortium was aiming at developing and the design process they implemented to reach this goal. If the artefact's characteristics changed during the project, we focused in our assessment on the characteristics that were stabilized towards the end of the project.

Our assessment method is based on a scorecard checklist. It is originally devised using some dimensions identified through the research led under the ASIRPA [acronymed for 'socio-economic analysis of impacts of public agronomic research'] project (Colinet et al., 2014). We adjusted it to account for dimensions to assess the contribution to sustainability ofthe solutions that we observed. Such dimensions were defined through the literature review completed as described under section 2.2. Table 2 provides an illustration of this scorecard checklist, showing all the criteria employed to assess how closely the innovation prototype and the innovation process meet the specific criteria analysed here (and which had not been formulated by the research team itself). Rating scheme runs from green to amber to red, where green is closest to objectives and red is furthest away. 
Analysis of the innovation prototype

Have the impact of the artefact on system sustainability been assessed?

No impact analysis was done. Some impacts have been analysed. Impact analysis realized.

Does the innovation prototype propose solutions to sustainable development (SD) challenges?

The innovation does not SD is part of the objectives, but it is SD is the central purpose of answer to SD challenges. not the central aspect. the concept.

Does the innovation prototype propose an integrated set of solutions to several sustainable development (SD) issues?

Only one aspect of SD has Several aspects taken into account, A wide diversity of aspects been taken into account. but important ones not considered. have been taken into account.

Does the innovation prototype proposed have substantial beneficial impact?

The impact has been The impact has been measured and The impact has been measured measured and is negative. is positive but not important.

Is the innovation prototype novel?

The interviewees knew about The interviewees knew about some They did not know about any several other similar projects. other similar projects ( 1 or 2$)$ other similar projects.

Does the innovation prototype propose solutions that can be generalized out to all other locations?

The innovation cannot be The innovation can be developed in The innovation can easily be developed in other a limited number of geographies or developed in other zones.

geographies. $\quad$ it needs several modifications.

Could the innovation prototype eliminate constraints upstream or downstream (U or D) of the value chain (green) or can it create new ones (red)?

U\&D have not been U\&D have partially been U\&D considered: innovation considered and the innovation considered: concept might create can lift constraints.

creates new constraints. new constraints.

Is the innovation prototype radically innovative?

The innovation is The innovation would imply a weak The innovation would imply incremental. Its development modification of existing networks the use of new types of would not imply a or types of knowledge used. knowledge, the destruction of fundamental modification of existing networks or types of knowledge used.

Did the innovation concept emerge from a coupled innovation process?

The concept concerns only The concept has been developed in one part of the value chain. order to build on a recent innovation in another part of the value chain.

Analysis of the innovation process

Is the innovation process open to outgroups?

A small number of actors Various types of actors \& fields outside the project involved involved, but marginally and during in a very weak manner. limited number of project stages. existing networks and the creation of new ones, creating value added.

Did the innovation concept emerge from systematic thinking at value-chain scale?

Issues from other parts of the Issues from other parts of the value Issues from other parts of the value chain have been weakly chain have partially been value chain have been taken integrated. integrated.

Did the innovation process involve/engage several scientific disciplines?

Only one scientific discipline Several scientific disciplines were The lead scientists were from was involved. involved, but the lead scientists various scientific disciplines. were all from the same discipline.

Importance of scientific, technical, economic, social, political [etc.] aspects in the problem targeted? Some aspects were factored Those aspects were taken into Those aspects were taken into in an inadequate way, leading account in an insufficient manner. to blockages. account in a comprehensive manner. 
Some criteria have been more difficult to assess than others. This is namely the case for the analysis of radicality. We used the definition of Carillo-Hermosilla et al. mentioned in section 2.2 and tried to assess the magnitude of the impact that the development of the artefact would have on the types of knowledge used and the networks involved. We considered a concept as radical if it implied the substitution of major stakeholders by others. It was for instance the case when the concept would imply the substitution of oil by biomass products as inputs in the industrial processes.

Our method was based on a qualitative analysis whose results could be discussed: one could have reached other conclusions with an analysis based on a different standards or goals. This is why, for each project, we justified of the color attributed to each criteria based on the specific characteristic of the project in a separate table. Our purpose was to stimulate discussion, since our analysis was limited by the time of the study.

\section{RESULTS AND DISCUSSION}

\subsection{Results}

Cross-comparison of the analyses led on all four case-projects highlights a number of overlapping patterns, as illustrated in Table 3.

First, all four projects propose new solutions, at least three of which we can qualify as radical (caseproject \#1, at its scale of development, has finally materialized as visibly less radical as was originally envisaged). Indeed, for all of the other three, their implementation in existing socio-technical systems would lead to a transformation of the upstream and/or downstream value chains. Note that in all four projects, we struggled to assess their contribution to sustainable development policy, either because no impact assessment had been planned or because the assessment completed had been grossly simplified or was more guesstimate than measurement. A common denominator to all four projects was that none of them were striving to take on board the requirements (e.g. interdisciplinary work at least) which a coupled innovation process as defined under section 2.1 will imply.

The observation of no coupled innovations aligns to the resources mobilized over the course of the innovation process, and chiefly the types of knowledge mobilized. Figure 2 shows that even when projects integrate actors from different stages of the value chains, their interactions remain limited, both between themselves and regarding the number of stages in which they collaborate (case of project 4 in particular). Moreover, knowledge about the future market and the socio-technical systems for inserting future innovations, is not always taken into account in projects. When they are, this is generally carried out late with experts external to the projects. The expert's knowledge is little taken into account or too late, as the strategic guidelines have already been established.

In their work Lenfle \& Midler (2009) illustrate the differences between exploration and development projects: "“'development" refers to a situation where the technical and market knowledge associated with the project are well-known ... On the other hand, "exploration" refers to a situation where the technology and the market have to be explored.... Exploration projects are meant to support the use of a technical innovation, a new practice, a new business model, etc. which, by definition, are not stabilized. As a result, the team will have to explore and develop new knowledge, which adds great uncertainty to the process". The projects we analysed, which involved exploration actions for all their stakeholders, were also all managed using project management methods required by the calls for projects and which are method derived from exploitation projects. As a result, we can clearly question the real possibilities that these management methods offer in the context of not only exploration projects but also projects that should be highly interdisciplinary. This interdisciplinarity requires time, for everyone to immerse themselves in each other's cognitive and decision-making paradigms. Traditional project management methods seem inappropriate for such objectives.

The first-hand accounts from the actors interviewed do confirm the role of the formulation of calls for government-funded projects, peer review of the projects themselves, and the career advancement processes for researchers where performance assessment is based on scholarship output and thus privileges pure in-discipline papers.

Note too that short-timeframed calls for projects prompt researchers to tend to turn towards familiar networks in order to quickly form a consortium of people that have shared experience working together, which makes it easier to get a new proposal put together. We also identified a second form of limit, this time linked to access to available equipment for leading the research work. Practical inability to mobilize new experimental setups due to financial squeeze and availability reasons (not 
enough time get trained and engineer new experimental protocols) are also barriers to breaking out from regular routine research practices. However, the process producing eco-innovation requires a flexibility of practice that simply does not converge with these contingency factors.

Table 3. Comparative roll-up of the four projects

\begin{tabular}{|l|l|l|l|l|}
\hline \multicolumn{1}{|c|}{ Concept analysis } & Project 1 & Project 2 & Project 3 & Project 4 \\
\hline $\begin{array}{l}\text { Have the impacts of the artefact on } \\
\text { system sustainability been assessed? }\end{array}$ & & & & \\
\hline $\begin{array}{l}\text { Does the concept propose solutions to } \\
\text { sustainable development challenges? }\end{array}$ & & & & \\
\hline $\begin{array}{l}\text { Does the concept propose an integrated } \\
\text { set of solutions to several sustainable } \\
\text { development problems? }\end{array}$ & & & & \\
\hline $\begin{array}{l}\text { Does the concept proposed have } \\
\text { substantial beneficial impact? }\end{array}$ & & & & \\
\hline Is the concept novel? & & & \\
\hline $\begin{array}{l}\text { Does the concept propose solutions } \\
\text { that can be generalized out to all other } \\
\text { geographies? }\end{array}$ & & & & \\
\hline $\begin{array}{l}\text { Could the concept eliminate constraints } \\
\text { upstream or downstream of the value } \\
\text { chain (green) or can it create new ones } \\
\text { (red)? }\end{array}$ & & & & \\
\hline Is the concept radically innovative? & & & & \\
\hline $\begin{array}{l}\text { Did the concept emerge from a coupled } \\
\text { innovation process? }\end{array}$ & & & & \\
\hline Analysis of the innovation process & & & \\
\hline $\begin{array}{l}\text { Is the innovation process open to } \\
\text { outgroups? }\end{array}$ & & & & \\
\hline $\begin{array}{l}\text { Did the concept emerge from } \\
\text { systematic thinking at value-chain } \\
\text { scale? }\end{array}$ & & & & \\
\hline $\begin{array}{l}\text { Did the innovation process } \\
\text { involve/engage several scientific } \\
\text { disciplines? }\end{array}$ & & & & \\
\hline $\begin{array}{l}\text { Did the innovation process factor in the } \\
\text { scientific, technical, economic, social, } \\
\text { political [etc.] components of the } \\
\text { problem being tackled? }\end{array}$ & & & & \\
\hline
\end{tabular}

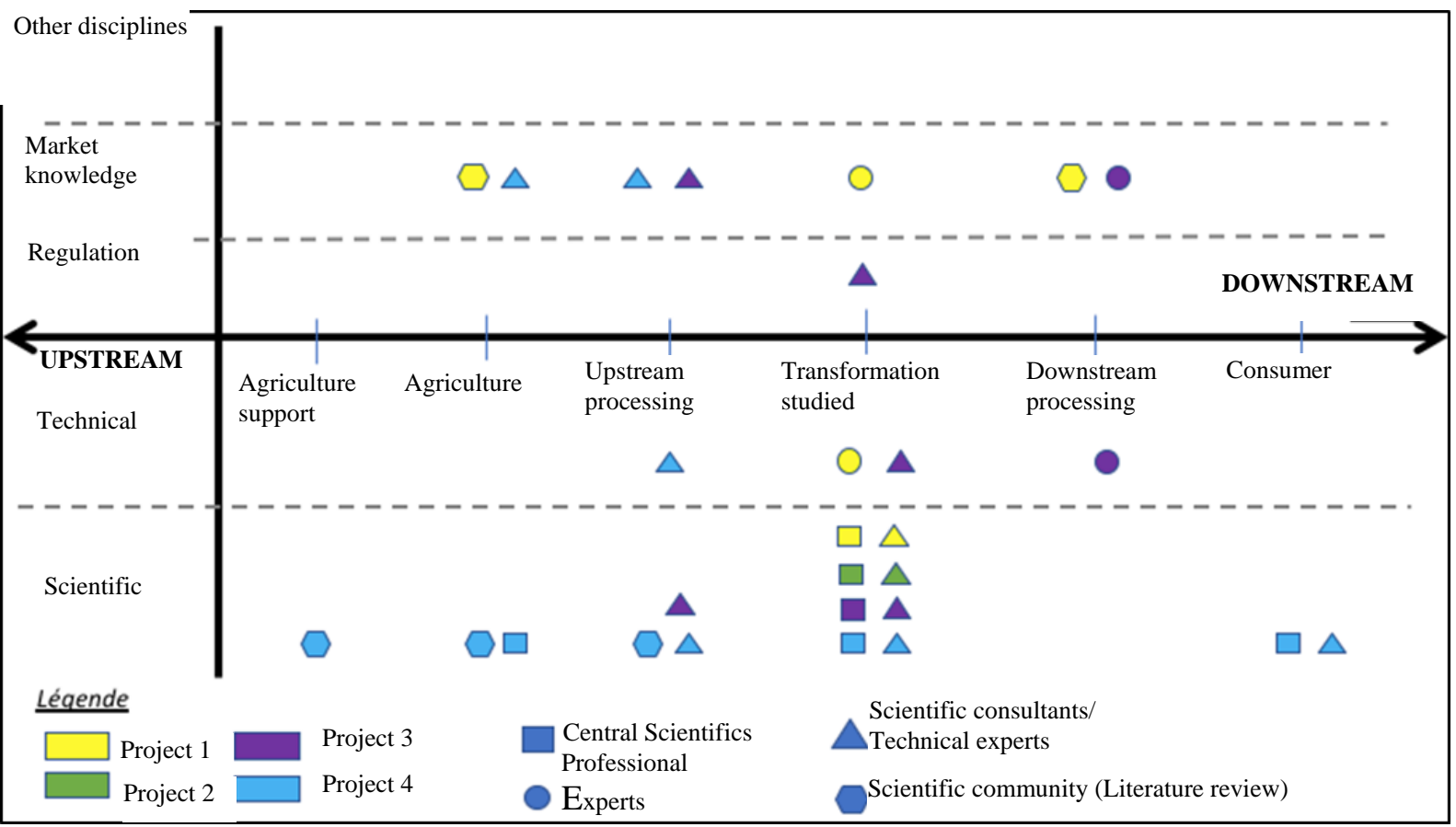

Figure 2. Types of knowledge mobilized in the four projects analysed 
The concepts developed were relatively radical in all four projects. This degree of radicality aligns to the fact that each of these projects emerged through encounters between people from different background disciplines or fields of activity. These people therefore had to learn to recombine their collective knowledge in order to propose new avenues to innovation or at least enable the project's lead $\mathrm{PhD}$ student make the recombination happen. The system-of-actors ecology maps that we put together (see figure 1) effectively show that the $\mathrm{PhD}$ students played a lead interfacing disciplines inside the project community. However, the researchers interviewed had sufficiently broad network connections to renew and refresh the knowledge used in their projects, thus enabling a certain degree of radicality to emerge. Nonetheless they did not integrate radically different approaches to those mobilized in their traditional 'home' environments. We did not, for example, find any alliance syndicating human and social sciences with hard sciences and life sciences inside the same one project. One likely explanation for this pattern could be the that calls for proposals, which make it practically an obligation to federate teams of researchers from different disciplines to collaborate on a single research problem, is already such a laborious exercise that it leads consortia to choose disciplines which have more proximity in terms of focus or paradigms. This limit to crossdisciplinarity may explain that no project presented innovation projects that were cast between agriculture and processing. When asked about this possibility of opening out to other fields of science, the researchers interviewed self-identified as ill-equipped to change mindset on this front, for three reasons: the difficulty identifying actors with which it would make sense for them to collaborate on unearthing new avenues to explore; the lack of resources - i.e. methods or practices - that would serve as a common language for establishing a problem to solve and shared objectives to work towards; the lack of investable time on the initial socialization stage to create a shared paradigm and understand each stakeholder's expectations.

Finally, a limiting factor of the projects for achieving ambition initially formulated regarding ecological transition was their environmental performance assessment. Our case-study material on this issue points to the following learnings:

- Without upstream or mid-stream analytical tools to evaluate the environmental performance of the innovation, researchers are left to rely on their common sense.

- For researchers, impact assessment is often synonymous with LCA. However, the LCA can prove under-adapted to the analysis of non-stabilized artifacts, and is not enough to rank the impacts under study. Furthermore, it is generally a backward-looking analysis and it ignores or has difficulty dealing with certain impacts such as biodiversity.

- In situations where finances are tight, the environmental impact analysis does not appear a priority for the researchers or for institutions funding research projects who do not all ask for this dimension in projects.

This evidence surfaces an issue surrounding the organizations funding the research, as any real policy to develop eco-innovations to address sustainable development challenges should come with some kind of value-mechanism system for efforts to put metrics on the real impact of research work done. It also surfaces how projects need to be financed with enough resources to get these actions done in the first place. Note that the environmental assessment experts still find it a big challenge to propose impact assessment metrics early on in upstream innovation-process phases and across a broad enough scope to encompass the global challenges facing their industries, before progressively refining the assessment metrics as and when solutions engineered are progressively redefined.

\section{CONCLUSION}

Here we present research that used case studies to illustrate and explore the two research questions set out in introduction. Each case-project demonstrated a strong multidisciplinary component that enabled relatively radical innovations to emerge. However, we found that the level of radicality remained limited - due to the lack of crossdisciplinarity in the projects (the one identified being the result of the work of the doctoral student who interfaces the different expertise of the project but who often leaves the team afterwards), and due to the lack of project articulation with wider sustainability challenges to guide the definition of target objectives supporting sustainable development. This potential methodological gap translates into underpowered tools and methods for environmental assessment in 
upstream project phases, making it impossible to articulate these tools with those classically used in the detailed solution design and definition phases (typically LCA or allied methods).

However, these findings need to be consolidated by further complementary analyses on both similar case-study and different case-study configurations. Here we showed that the projects analysed were articulated around $\mathrm{PhD}$ students, which was one of the selective variables that we opted for to keep the projects analysed in a manageable frame. We also showed that the $\mathrm{PhD}$ students played a lead role in interfacing and integrating disciplines inside the project community. We now need to analyse a further set of projects with broader-reaching scopes to determine how the projects manage to generate and handle crossdisciplinarity without this central lead $\mathrm{PhD}$ student role. An additional dimension that remains to be assessed is the specificities of these results dealing with projects involving life sciences. It would be relevant to compare these results with those of projects involving different fields of experimentation.

\section{REFERENCES}

Bergek, A., Jacobsson, S., Carlsson, B., Lindmark, S. and Rickne, A., (2008), “Analyzing the functional dynamics of technological innovation systems: A scheme of analysis", Research Policy

Bonnetto, E., Yannou B, Bertoluci, G., Boly V and Alvarez, J. (2016), “A categorization of customer concerns for an OT front-end of innovation process in IT/OT convergence." 12th ICORD Conference; Dubrovnik.

Callon, M., Lhommer, R. and Fleury, J. (1999), "Pour une sociologie de la traduction en innovation," Recherche \& Formation, Vol. 31, pp. 113-126.

Carillo-Hermosilla, J., Del Rio, P. and Konnolat, T., (2010), "Diversity of eco-innovations: Reflections from selected case studies”, Journal of Cleaner Production Management, vol. 18, pp. 1073-1083.

Colinet, L., Joly, P.B, Gaunand, A. and Lemarié, S., (2014), “ASIRPA - Analysis of the Impacts of Public Agronomic Research," INRA Report, p. 64.

Dubois, M., (2005), "Scientific action: interpretative and explanatory models in the sociology of science," L’année sociologique, Vol. 55, pp. 103-125.

Enengel, B., Muhar, A., Penker, M., Freyer, B., Drlik, S. and Ritter, F. (2012), “Co-production of Knowledge in Transdisciplinary Doctoral Theses on Landscape Development - An Analysis of Actor Roles and Knowledge Types in Different Research Phases," Landscape and Urban Planning, 105, 1-2: 106-117. sociologique Landscape and Urban Planning, Vol. 105, pp. 106-117.

FAO (2015), "Feeding the world in 2050," Rome.

Gaglio, G. (2011), “Sociologie de l'innovation”, coll. «Que sais-je ? », PUF, Paris, 2011, p. 128.

Klein, K.J. and Knight, A.P., (2005), "Innovation Implementation: Overcoming the Challenge", Current Directions in Psychological, Vol. 14, No. 5, https://doi.org/10.1111/j.0963-7214.2005.00373.x

Meynard, JM, Jeuffroy, MH, Le Bail, M, Lefèvre, A, Magrini, MB and Michon, C. (2017), "Designing coupled innovations for the sustainability transition of agrifood systems". Agric Syst Vol. 157, p. 330-339. https://doi.org/ 10.1016/j.agsy.2016.08.002

Nonaka, I. and Toyoma, R. (2003), "The knowledge-creating theory revisited: knowledge creation as a synthesizing process," Knowledge Management Research \& Practice, Vol. 1, No. 1, pp. 2-10.

Reed, M.S., Graves, A., Dandy, N., Posthumus, H., Hubacek, K., Morris, J., Prell, C., Quinn, C.H. and Stringer LC. (2009), "Who's in and why? A typology of stakeholder analysis methods for natural resource management", Journal of Environmental Management, Vol. 90, pp. 1933-49 https://doi.org/10.1016/j.jenvman.2009.01.001

Thiard et al. (2013), "Mission on support mechanisms for partnership research," French Ministry of Economy and Finance, Higher Education and Research.

Roelofsen, A. et al. "Stakeholder interaction within research consortia on emerging technologies: Learning how and what?” Research Policy, Vol. 40 No. 3, pp. 341-354.

Yannou-Le Bris, G. and Serhan, H. (2018), “The knowledge value chain for eco-design and eco-innovation in food - Case study of ECOTROPHELIA projects." Innovation Network, (Ed.), 8th Forum Innovation, Nîmes, France.

\section{ACKNOWLEDGMENTS}

This research was funded by AgroParisTech Research Funds.

This work was realized under the umbrella of the Initiative for Design in Agrifood Systems (IDEAS). 